\title{
Reducing Vulnerability to Natural Hazards
}

\author{
by Harold D. Foster
}

\begin{abstract}
Nowhere on earth is risk free. Disasters can occur anywhere. A wide variety of safety delivery systems, therefore, have evolved to keep losses within acceptable limits. These networks generally include participatory groups such as financial institutions, the scientific community, architects, realtors, the media, government and the public. Since the range of disaster agents is increasing, a series of six safety-related activities must be carried out in a logical sequence, if community safety is to be increased. These strategies are risk mapping, increasing safety through better design, disaster simulation, the establishment of warning systems, preparation of disaster plans and planning for reconstruction before damage occurs.
\end{abstract}

\section{Introduction}

Nowhere on earth is completely safe. This is because the surface of our planet is an intricate risk mosaic, every region being threatened by a variety of both natural and man-made hazards. While it is impossible to remove all such risk, associated losses can be reduced by planning for greater safety through the adoption of numerous disaster mitigation strategies. This process of deliberate risk management normally involves the operation of complex decision-making networks, termed "safety delivery systems" by this author. A heuristic model of such a system is presented as Figure 1. This diagram illustrates that the reduction of risk from major hazards almost invariably involves international, national, regional, and local governments; the scientific community; financial institutions (such as insurance companies and banks); developers ; architects ; realtors; the media; the owners and renters of private homes and commercial buildings and the general public.

Regardless of the country involved or indeed the hazard under consideration, each safety delivery system has defined, either explicitly or implicitly, what for it is an acceptable level of risk. It then attempts to achive this target by the adoption of strategies which are intended to ensure that losses from the hazards that it is managing do not rise above this threshold. Naturally, the acceptable level of risk from particular hazards varies from country to country and indeed from region to region. As a result, societies evolve in

\footnotetext{
* B.Sc., Ph.D., Professor of Geography, University of Victoria, British Columbia, Canada.
} 


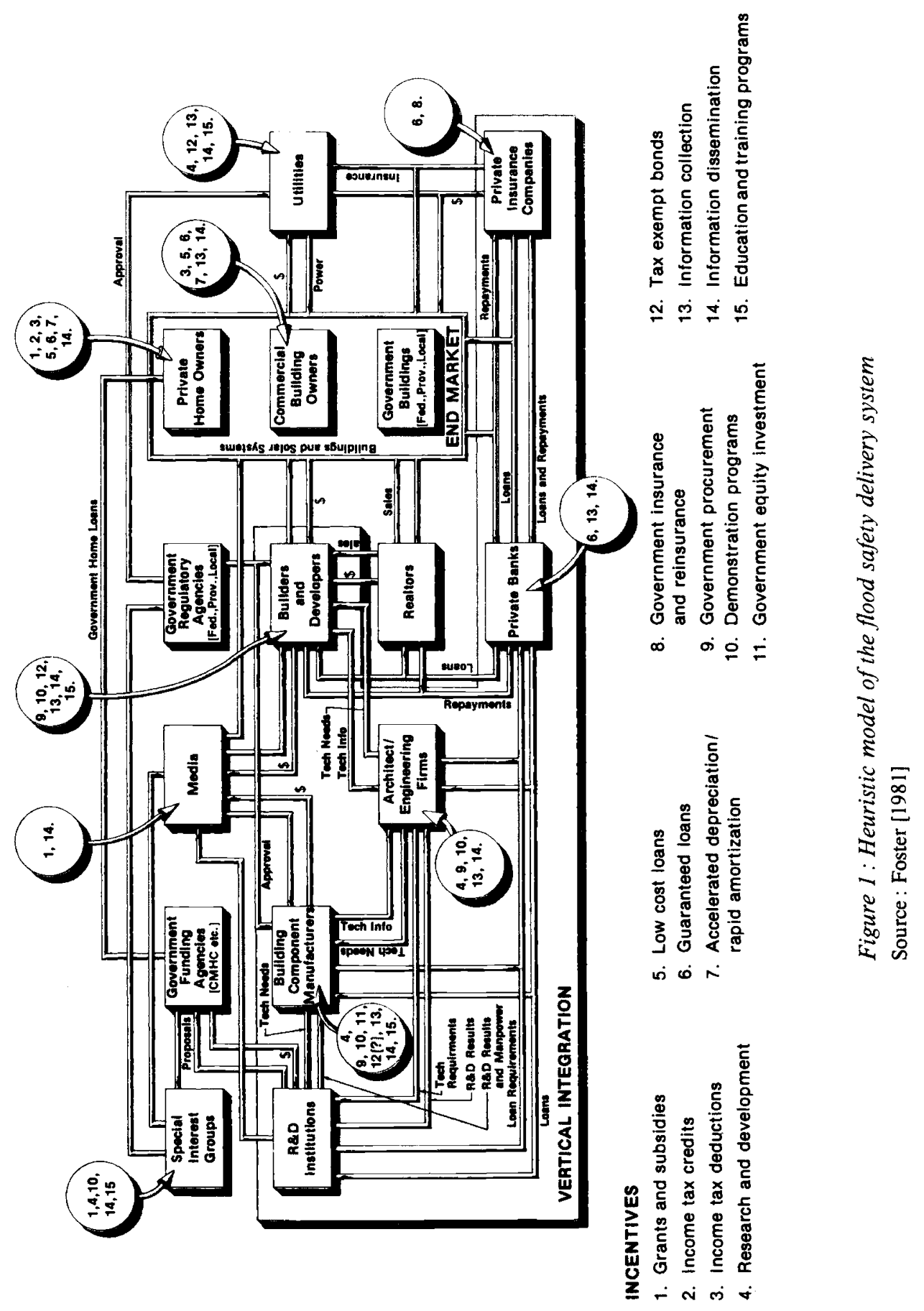


a manner that allows them to operate within specific levels of tolerance for natural and man-made events. Boundaries to what is in effect acceptable risk are defined either by laws or by common practice. Regulations such as public health and building codes usually identify the maximum event that should be guarded against and, as a result, govern the losses that must be accepted. The associated level of safety reflects a variety of factors including the availability of capital and manpower, past experience, needs, wants and priorities.

Such safety delivery systems are not static, they evolve. Social goals may alter and, in consequence, the public may demand greater protection from earthquakes, floods, hurricanes or other hazards. Most displays of dissatisfaction with a particular safety delivery system usually take place after a disaster which clearly demonstrates that existing standards are too low. As a result, the law or associated codes and regulations may be altered and the safety delivery system involved modified to meet new objectives. In addition, change and associated improvements in security can be achieved by the provision of incentives designed to promote the adoption of innovation. These incentives may be in the form of capital, for example grants and subsidies, income tax credits, accelerated depreciation or tax exemptions which are provided to different groups within the safety delivery system. They can also involve the provision of information through research, development, demonstration, education and training programs. The points within such safety delivery systems where these incentives can best be used to reduce losses are also illustrated in Figure 1 (Foster [1981]).

Regardless of the hazard involved, in theory at least, every safety delivery system can choose whether or not to implement four basic groups of mitigation strategies. Typically, these involve measures to modify or remove either the hazard or the infrastructure at risk, or they seek to accommodate accepted losses with minimum social disruption (Table 1). In practice, however, the choice of strategies may be limited by such factors as a lack of scientific knowledge about the hazard and its probable impact, an absence of appropriate technology, high cost or legal and social objections to implementation. The selection of mitigation strategies is also influenced by the training of those involved in managing the safety delivery system and the perceptions and attitudes of various special interest groups and the general public who are served by it. In addition, some hazards strike so rarely, as for example meteorites, or cause so little damage that no safety delivery system exists for them. In such cases the typical response by those adversely affected is loss bearing.

\section{Reducing disaster losses through comprehensive planning}

Although there are major differences between safety delivery systems for individual natural hazards there are also significant similarities. Many networks, for example, generally operate in relative isolation. They are designed to reduce the risks from a single disaster agent such as flooding, or from a group of related hazards, for example mass movement phenomena. As a result, there is often little coordination of effort between managers of such systems. Safety delivery networks also often involve various levels of government - state, regional and local. To reduce losses, cooperation is normally required between them. For major hazards, international coordination is often also essential, as for example is the case with Pacific tsunamis. Frequently, however, land use decisions are 


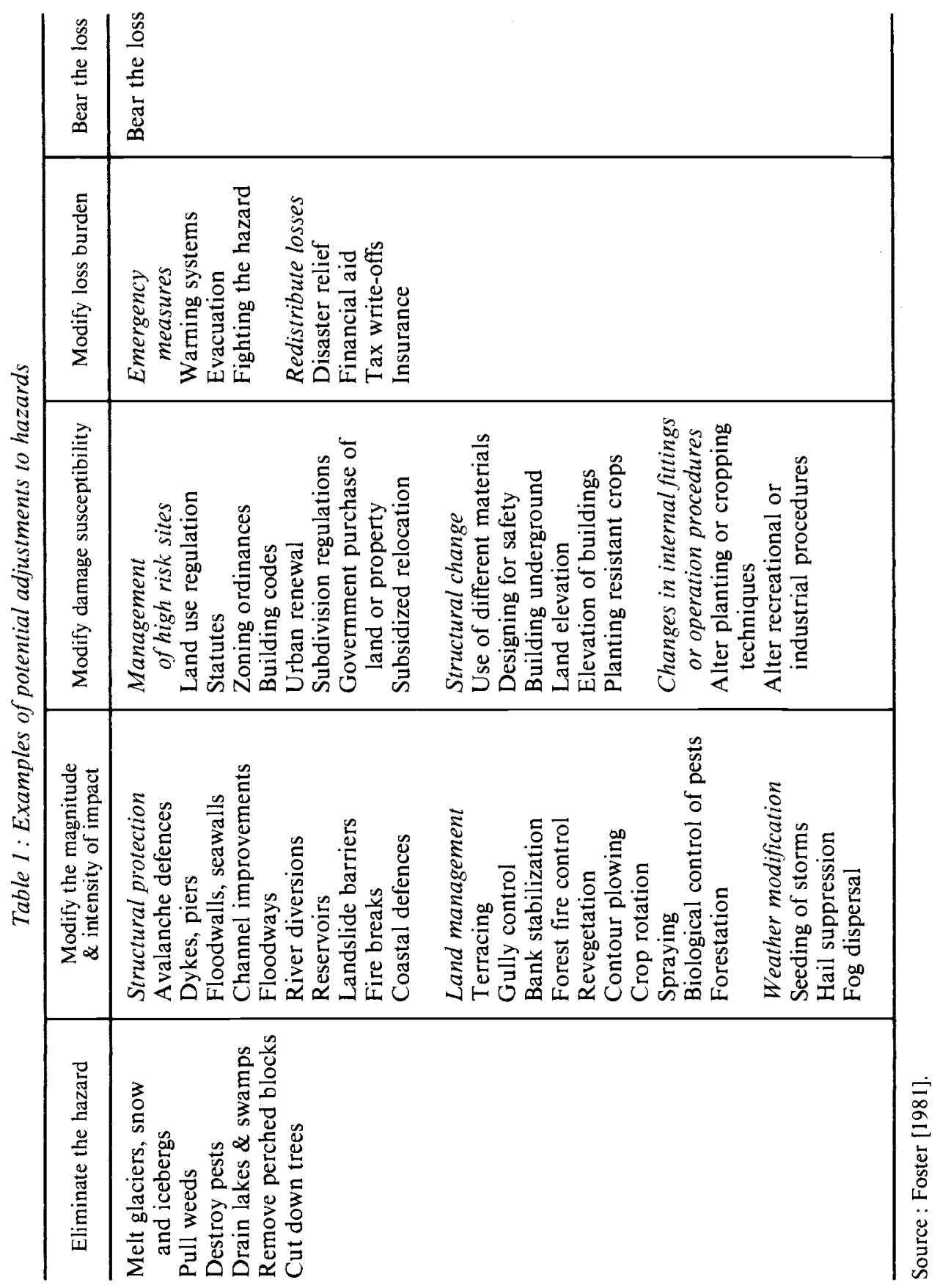




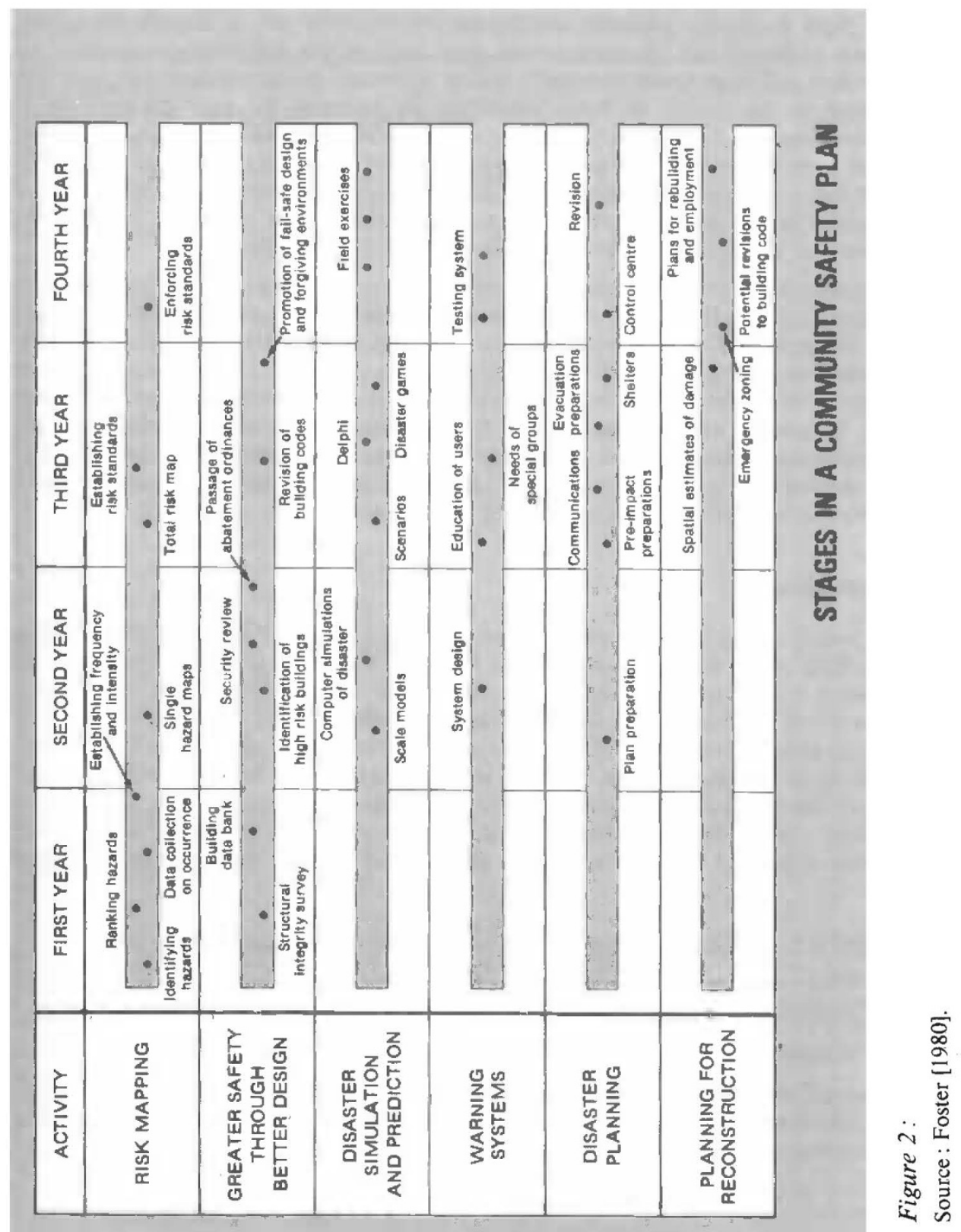


made by local municipal planners and elected officials who fail to identify the spatial distribution of hazard risk. In consequence, they often permit extensive development on high risk sites and large losses inevitably follow. National or international aid may then be provided for the victim. In many countries, the necessity for state governments to respond to disasters, caused by risk-taking at the local level, has led to the increasing participation of higher orders of government in the identification of risk and the control of related land use decisions. A spectrum of participation can be identified which stretches from simple hazard data collection to the purchase of high risk sites by national governments so preventing unacceptable risk-taking at the local level.

If disaster losses are to be reduced significantly, the reduction of risk must be given greater priority at lower levels of decision making. Perhaps the best way of achieving this is by the integration of a variety of safety delivery systems into comprehensive planning. This requires the development of a community safety plan, the various stages of which are illustrated in Figure 2. Such a plan might best be designed by an advisory committee reporting to elected officials whose role it is to ensure that implementation of the comprehensive plan decreases risk. The diagram is intended to demonstrate that a variety of safety-related activities must be carried out in a logical sequence if losses are to be reduced by the successful implementation of such planning at the local level.

\section{Risk mapping}

The initial step in the production of a community safety plan involves risk mapping, the identification of spatial variations in threat. This process must begin with the identification of any hazards which can be expected to influence the region. To this end, a wide range of literature must be reviewed, data collected and interviews conducted. Information should be gleaned from a variety of sources such as newspaper files, diaries, recollections of the elderly, fire, hospital and insurance records. Naturally, scientific literature is also of great value, particularly state geological surveys, and that produced by the medical, climatology, geography and urban planning departments of colleges and universities. Table 2 is a simple check list, provided by the British Columbia Provincial

Table 2: Peacetime disasters : Ratings of community disaster probability

Name of Community

Date

Name of Respondent

Position

1. How would you rate the probability of the following events in your community, within this coming decade? Please rate them in terms of the following 6-point scale by circling the appropriate number.

$$
\begin{aligned}
& 0 \text { - Not applicable to my community } \\
& 1 \text { - Not probable } \\
& \text { 2 - Low probability } \\
& 3 \text { - Moderate probability } \\
& 4 \text { - High probability } \\
& 5 \text { - Nearly certain }
\end{aligned}
$$

(continued) 


\begin{tabular}{|c|c|c|c|c|c|}
\hline & 0 & 1 & 2 & 3 & \\
\hline BLIZZARD OR MASSIVE SNOWSTORM & & 1 & 2 & 3 & 4 \\
\hline 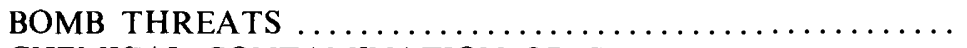 & & 1 & 2 & 3 & \\
\hline CHEMICAL CONTAMINATION OR SPILL $\ldots \ldots \ldots \ldots \ldots$ & 0 & 1 & 2 & 3 & \\
\hline CIVIL DISTURBANCE OR RIOT $\ldots \ldots \ldots \ldots \ldots \ldots \ldots \ldots$ & 0 & 1 & 2 & 3 & \\
\hline 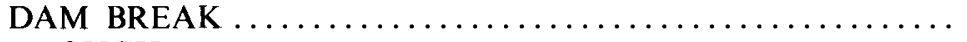 & 0 & 1 & 2 & 3 & \\
\hline DROUGHT . . & 0 & 1 & 2 & & \\
\hline EARTHQUAKE & 0 & 1 & 2 & 3 & \\
\hline ELECTRIC POWER BLACKOUT & 0 & 1 & 2 & & \\
\hline EPIDEMIC . ............... & 0 & 1 & & & \\
\hline FIRE & 0 & 1 & & & \\
\hline FLASH FLOOD & 0 & 1 & & & \\
\hline FOREST OR BRUSH FIRE $\ldots \ldots \ldots \ldots \ldots \ldots \ldots \ldots \ldots \ldots$ & 0 & 1 & & & \\
\hline FREEZING ICE STORM .. & 0 & 1 & & & \\
\hline HOSTAGE INCIDENT . & 0 & 1 & 2 & 3 & \\
\hline HURRICANE ....... & 0 & 1 & 2 & 3 & \\
\hline LOST PERSONS & 0 & 1 & 2 & 3 & \\
\hline MAJOR FROST AND FREEZE & 0 & 1 & & 3 & \\
\hline MAJOR GAS MAIN BREAK .. & 0 & 1 & & & \\
\hline MAJOR HAIL STORM $\ldots \ldots \ldots \ldots \ldots \ldots \ldots \ldots \ldots \ldots \ldots$ & 0 & 1 & & 3 & \\
\hline MAJOR INDUSTRIAL ACCIDENT .. & 0 & 1 & & 3 & 4 \\
\hline MAJOR ROAD ACCIDENTS ....... & 0 & 1 & 2 & 3 & 4 \\
\hline MAJOR WATER MAIN BREAK .. & 0 & 1 & 2 & 3 & 4 \\
\hline MINE DISASTER $\ldots \ldots \ldots \ldots \ldots \ldots$ & 0 & 1 & & 3 & \\
\hline MUD OR LANDSLIDE & 0 & 1 & 2 & 3 & 4 \\
\hline$\ldots \ldots \ldots \ldots \ldots \ldots$ & 0 & 1 & & 3 & 4 \\
\hline PIPELINE EXPLOSION . & 0 & 1 & & & \\
\hline PLANE CRASH IN COMMUNITY & 0 & 1 & & 3 & 4 \\
\hline RADIOLOGICAL ACCIDENTS .... & 0 & 1 & 2 & 3 & 4 \\
\hline RIVER FLOOD $\ldots \ldots \ldots \ldots \ldots \ldots$ & 0 & 1 & 2 & 3 & 4 \\
\hline SEVERE FOG EPISODE $\ldots \ldots \ldots \ldots \ldots \ldots \ldots \ldots \ldots \ldots$ & 0 & 1 & 2 & 3 & 4 \\
\hline SHIP DISASTER IN HARBOUR OR NEARBY COAST ... & 0 & 1 & 2 & 3 & \\
\hline SMALL BOATS, LOST OR ACCIDENTS $\ldots \ldots \ldots \ldots \ldots \ldots$ & 0 & 1 & 2 & 3 & 4 \\
\hline SMOG EPISODE $\ldots \ldots \ldots \ldots \ldots \ldots \ldots \ldots$ & 0 & 1 & & 3 & 4 \\
\hline SUDDEN WASTE DISPOSAL PROBLEM $\ldots$. & 0 & 1 & & 3 & 4 \\
\hline RAILWAY ACCIDENT $\ldots \ldots \ldots \ldots \ldots \ldots$ & 0 & 1 & & 3 & \\
\hline TORNADO $\ldots \ldots \ldots$ & 0 & 1 & 2 & 3 & 4 \\
\hline TSUNAMI $\ldots \ldots \ldots \ldots \ldots \ldots \ldots$ & 0 & 1 & 2 & 3 & 4 \\
\hline VOLCANIC ERUPTION OR FALLOUT & 0 & 1 & 2 & 3 & \\
\hline WATER POLLUTION $\ldots \ldots \ldots \ldots \ldots \ldots$ & 0 & 1 & 2 & 3 & \\
\hline WATER SHORTAGE. & 0 & 1 & & 3 & \\
\hline OTHER $\ldots \ldots \ldots \ldots$ & & 1 & & 3 & \\
\hline
\end{tabular}

Source: British Columbia Provincial Emergency Program. 
Emergency Program, which is designed to stimulate the interest of local communities in a variety of hazards, the consequences of which they may ultimately be forced to deal with. While not comprehensive, it provides a useful basis for hazard identification, the first step in risk mapping.

Ideally, direct observations, specifically taken to determine the frequency, magnitude and intensity with which disaster agents strike, are required to produce risk maps. While very incomplete, considerable data exist. The Smithsonian Institution [1971] has attempted to provide a complete worldwide listing of centres holding such information.

Medical statistics provide a valuable source of data for use in risk mapping. These are available from the statistics annuals of the World Health Organization and such bodies as the National Center for Health Statistics in the United States. These data permit regions or communities to determine how their mortality rate compares with those of other areas. In addition, changes in causes of death through time can be detected in a single community.

When displayed cartographically such data are essentially risk maps, showing the regional consequences of the impact of a variety of natural and man-made hazards. In its simplest form this information can be mapped to display global, national or local mortality patterns. Murray [1967], for example, cartographically illustrated the rate of death from all causes in the United States on a countrywide basis.

At a more sophisticated level, such mortality data are of value in allowing comparisons of death rates from individual diseases, hazards or fatal accidents. Howe [1979] has produced maps of the Greater London area showing differences in mortality ratios for suicide ; ischaemic heart disease ; cancer of the trachea, lung and bronchus; as well as chronic bronchitis. His maps generally establish a decline in mortality ratios outwards from the city centre (Figure 3 ).

In 1980 the Canadian federal government published The Mortality Atlas of Canada (Gray [1982]) which was designed to identify regional variations in causes of death. This illustrated, for example, a very high mortality from leukemia in St. Hyacinthe, Quebec. Research is now focussing on possible causes, including water quality, occupational risks and lifestyles. An interesting example of the value of cartographically displaying spatial variations in mortality also has been provided by "the cancer detectives ", Ger Ming, Yang and Li (NOVA [1980]). These scholars mapped the distribution of this illness in the Peoples Republic of China. They then focussed their attention on Lin Xian, a county where one out of every four deaths resulted from esophageal cancer, a higher proportion than for any other area in the world.

One important deficiency of mortality statistics is that they frequently fail to fully account for risks from rare events, such as flash floods or earthquakes. For this reason, it is important that the potentially large impact of relatively rare, highly destructive events is not overlooked. In such cases extrapolation must come from historical, archaeological, geomorphological, biological and geological evidence. For example, legends of catastrophe are commonplace since such events may form watersheds in the history of a society (Vitaliano [1973]). Major disaster agents including floods, volcanic eruptions, landslides and earthquakes leave a variety of sediments and biological damage in their wake which can be used to expand the historical disaster record, since the former remains thousands of years after the event (Crandell and Waldron [1969]). 


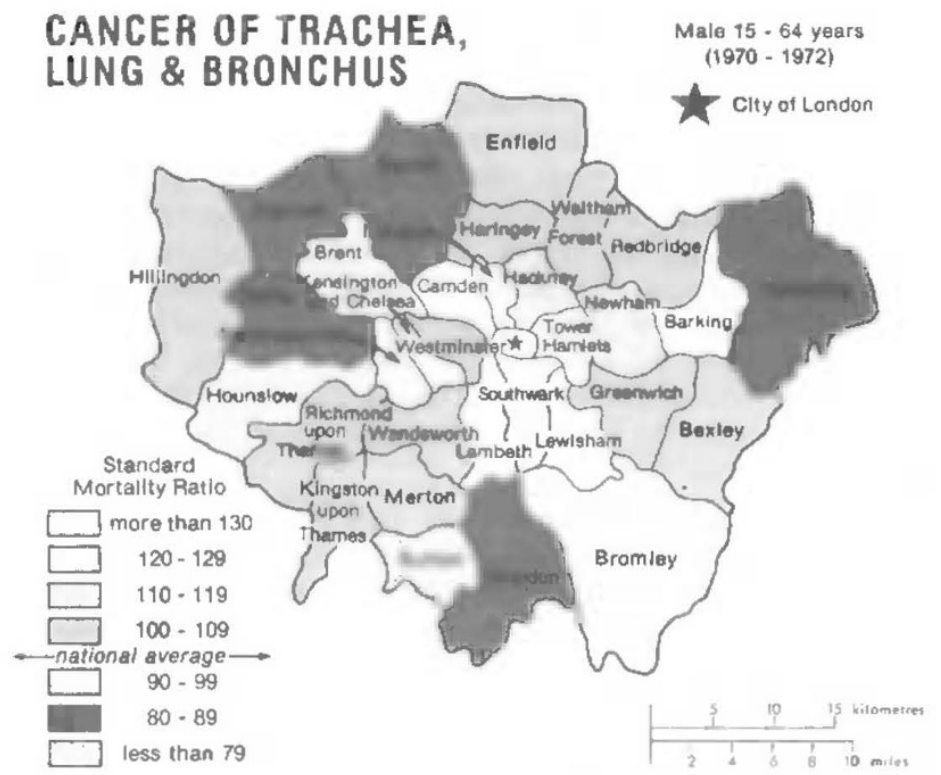

\section{ALL CAUSES}

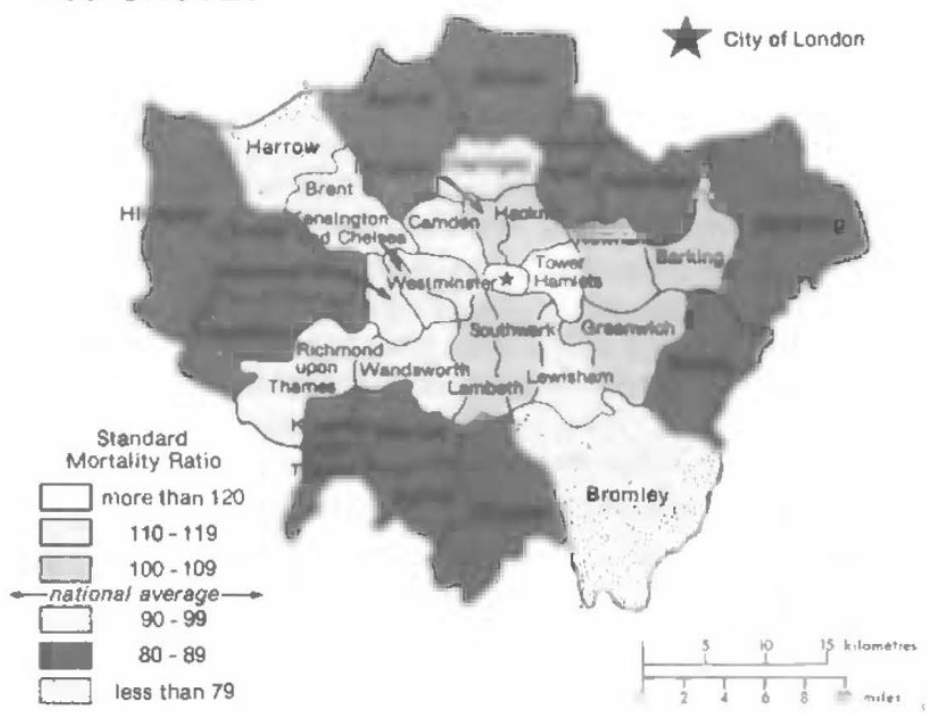

Figure 3 : Examples of mortality mapping, Greater London, England Source: Howe [1979]. 
Such data can also be used to prepare risk microzonations with planning value. Numerous examples can be cited. They include the maps produced by the flood delineation programs of the Japanese Geographic Survey Institute, the U.S. Corps of Engineers and the Canadian Federal Government. While such hazards maps frequently use historical data, they are also often strengthened by the incorporation of geomorphological and geological information. Numerous volcanic risk maps have been produced by the Volcanology Division of the Geological Survey of Indonesia. Progress has also been made in the production of microzonation maps showing spatial variations in risk from earthquakes, for example such documents are available for Sofia in Bulgaria, Bucharest, Galati and Arges in Romania and for several Turkish, Yugoslavian and Soviet cities (Karnik [1972]). Microzonation maps showing differing risk potentials have also been produced for areas suffering from coastal erosion, storm surges, tsunamis, avalanches and landslide hazards (Foster [1975]).

Certainly the most useful microzonations from a planning point of view are the multiple hazard-multiple purpose maps. These seek to show the total risk picture as a basis for rational locational decisions. To produce such maps, a common unit of comparison must be established, such as the life loss or injury potential, probable stress caused or the dollar losses to be expected from all hazards. Since such mapping is likely to be computerized, the production of a series of maps using all three of these units of measurement is almost as simple a procedure as that involved in the use of a single basis of hazard comparison. Where a selection must be made, monetary units have certain advantages over other alternatives since they allow benefit-cost relationships to be established and permit risk factors to be compared with other costs that vary with location, such as those due to transportation.

As far as the author is aware, the first such attempt to produce a total risk map was that by Wuorinen [1979]. This researcher mapped the spatial distribution of threat from individual hazards, such as flooding, coastal erosion, soil loss and earthquakes in the Saanich Peninsula, British Columbia, Canada. In the case of earthquakes, for instance, three hazard zones were established and the frequency with which seismic events in each reached specified intensities was established by consulting the Canadian National Building Code.

To estimate associated losses it was also necessary to know the value of the land and improvements affected by such events. To calculate the average value of one hectare of developed land in the Greater Victoria area, financial data were obtained from the B.C. Assessment Authority. These had originally been collected for taxation purposes (Table 3).

Table 3: Value of land and improvements

\begin{tabular}{l|c|c|c|c|r}
\hline & $\begin{array}{c}\text { Land } \\
\text { area } \\
\text { (ha) }\end{array}$ & $\begin{array}{c}\text { Land } \\
(\$)\end{array}$ & $\begin{array}{c}\text { Private } \\
\text { improvements } \\
(\$)\end{array}$ & $\begin{array}{c}\text { Total } \\
\text { improvements } \\
(\$)\end{array}$ & $\begin{array}{c}\text { Grand total } \\
(\$)\end{array}$ \\
\hline Victoria & 1878 & $152,033,160$ & $280,137,800$ & $348,146,273$ & $500,179,433$ \\
Oak Bay & 1046 & $261,464,089$ & $182,234,550$ & $227,793,198$ & $489,257,287$ \\
Esquimalt & 631 & $222,506,880$ & $141,889,734$ & $235,153,334$ & $457,660,214$ \\
TOTAL & 3555 & $636,004,129$ & $604,262,084$ & $811,092,805$ & $1,447,096,934$ \\
Value/ha & - & 178,879 & 169,975 & 228,123 & 407,002 \\
\hline
\end{tabular}

Source : B.C. Assessment Authority [1978] ; Wuorinen [1979]. 
Independent values for land and improvements (public and private) were required for the production of total risk maps since different disaster agents result in losses to various combinations of investments. To illustrate, earthquakes generally affect improvements only, while coastal erosion destroys both the land and the improvements thereon.

It was also essential to know what percentage of this property would suffer damage in earthquakes or other disaster agent impacts of differing intensities. Steinbrugge [1970] has already established such damage ratios, based on the cost of repairs for seismic events. These were determined from damage suffered in the San Francisco-Oakland metropolitan statistical area but were considered fairly applicable to Victoria.

These three types of information, the value of land and its developments, the expected frequency with which seismic intensities are to be expected, and the associated potential damage ratios, were then used to calculate the total anticipated loss per hectare per year in each of the earthquake risk zones (Table 4). In the lowest risk zone, annual earthquake

Table 4: Earthquake losses by zone

\begin{tabular}{c|rr|rr|rr}
\hline \multirow{2}{*}{$\begin{array}{c}\text { Annual } \\
\text { frequency }\end{array}$} & \multicolumn{2}{|c|}{ Zone 1 } & \multicolumn{2}{c|}{ Zone 2 } & \multicolumn{2}{c}{ Zone 3 } \\
\cline { 2 - 7 } & MMI & $\begin{array}{c}\text { Loss / } \\
\text { ha (\$) }\end{array}$ & MMI & $\begin{array}{c}\text { Loss / } \\
\text { ha (\$) }\end{array}$ & MMI & $\begin{array}{r}\text { Loss / } \\
\text { ha (\$) }\end{array}$ \\
\hline .150 & III & - & IV & - & V & 70 \\
.065 & IV & - & V & 30 & VI & 141 \\
.036 & V & 17 & VI & 78 & VII & 413 \\
.015 & VI & 32 & VII & 172 & VIII & 564 \\
.0081 & VII & 93 & VIII & 305 & IX & 447 \\
.0033 & VIII & 124 & IX & 182 & X & 182 \\
Total loss/ha/yr & & 266 & & 767 & & 1817 \\
\hline
\end{tabular}

Source: Wuorinen [1979].

related losses might be expected to be $\$ 266$ per hectare, rising to $\$ 767$ in moderate risk and $\$ 1,817$ in high risk areas. In a similar manner, the annual losses to be anticipated in low, medium, and high risk flood, costal, or soil erosion zones were also calculated (Table 5). Summing these values for each hectare resulted in a map showing total annual

Table 5 : Summary of potential annual dollar losses per hectare for the Saanich Peninsula

\begin{tabular}{lrrrc}
\hline & Zone I & Zone 2 & Zone 3 & Zone 4 \\
\hline Earthquake & 266 & 767 & 1817 & - \\
Flooding & 0 & 227 & 910 & - \\
Surface erosion & 0 & 3 & 9 & - \\
Coastal erosion & 0 & 960 & 1930 & 2880 \\
\hline
\end{tabular}

Source: Wuorinen [1979]. 
expected disaster losses for the Saanich Peninsula on which Greater Victoria is situated (Figure 4). The data collected demonstrated that for the four natural hazards considered, average annual disaster losses per hectare ranged from $\$ 156$ to some $\$ 4,600$.

Such multiple hazard-multiple purpose maps can, of course, be prepared for as many disaster agents as a region or municipality is subjected to. These hazards may be natural or man-made. Once their impact has been reduced to a common unit of measurement, risks from any source can be summed to give a comprehensive overview of potential losses. After such maps have been produced the next issue to be resolved is that of risk acceptability. The safety plan coordinator, his committee, and perhaps the general public must seek to agree on acceptable risk standards. These should reflect the careful balancing of potential losses and benefits (Puget Sound Council of Governments [1975] ; Foster [1980]).

\section{Greater safety through better design}

While primary and secondary losses from natural and man-made disasters can be greatly reduced by ensuring that the spatial variations in risk are integrated into planning, this in itself is insufficient (Figure 2). Safety must also be promoted through better design of buildings, inventions and land use activities. This can best be achieved by the promotion of six basic philosophies: structural integrity, operational compatibility, fail-safe design, forgiving environments, emergency strategy and user security. The author has described these in detail elsewhere and can only briefly discuss their significance here (Foster [1980]).

The structural integrity of a building is its physical adequacy for its intended function. Typically, major disaster areas are littered with the wreckage of buildings and utilities that have been unable to maintain their structural integrity under abnormal conditions. While architects and engineers do not, nor should they seek to ensure absolute safety, there is little doubt that improvement in construction practices can reduce casualties and property losses. To this end, design and construction should attempt to provide structures that meet established acceptable risk levels at the lowest cost. Collapse or damage may subsequently occur, however, because of errors made during design, construction, or use.

The need to design buildings capable of withstanding the impact of disaster agents was graphically illustrated in Tangshan, China, on 28 July 1976 . When a major earthquake occurred with its epicentre directly under the city, 352 multistorey buildings were seriously affected. Of these, 177 were completely destroyed, 85 suffered partial collapse, and 99 were severely damaged. Only four retained their structural integrity. In addition, 20 highway bridges collapsed and a further 211 suffered damage, as did 40 earth dams. Although no official death toll has been released, 750,000 fatalities have been estimated (Sullivan [1979]).

Rodin [1978] has identified four approaches to construction which are aimed at reducing hazards or mitigating their consequences. The first such method uses probability theory to calculate the likelihood that load may exceed strength. The second approach to providing structural integrity involves a historical review of building failures and the identification of the specific factors which have caused them. In this way it is expected that proneness to failure can be predicted and therefore reduced by taking advantage of adverse experience. One of the major problems with this technique is the collection of reliable data. Few engineers wish to broadcast their failures. To overcome this difficulty, a 

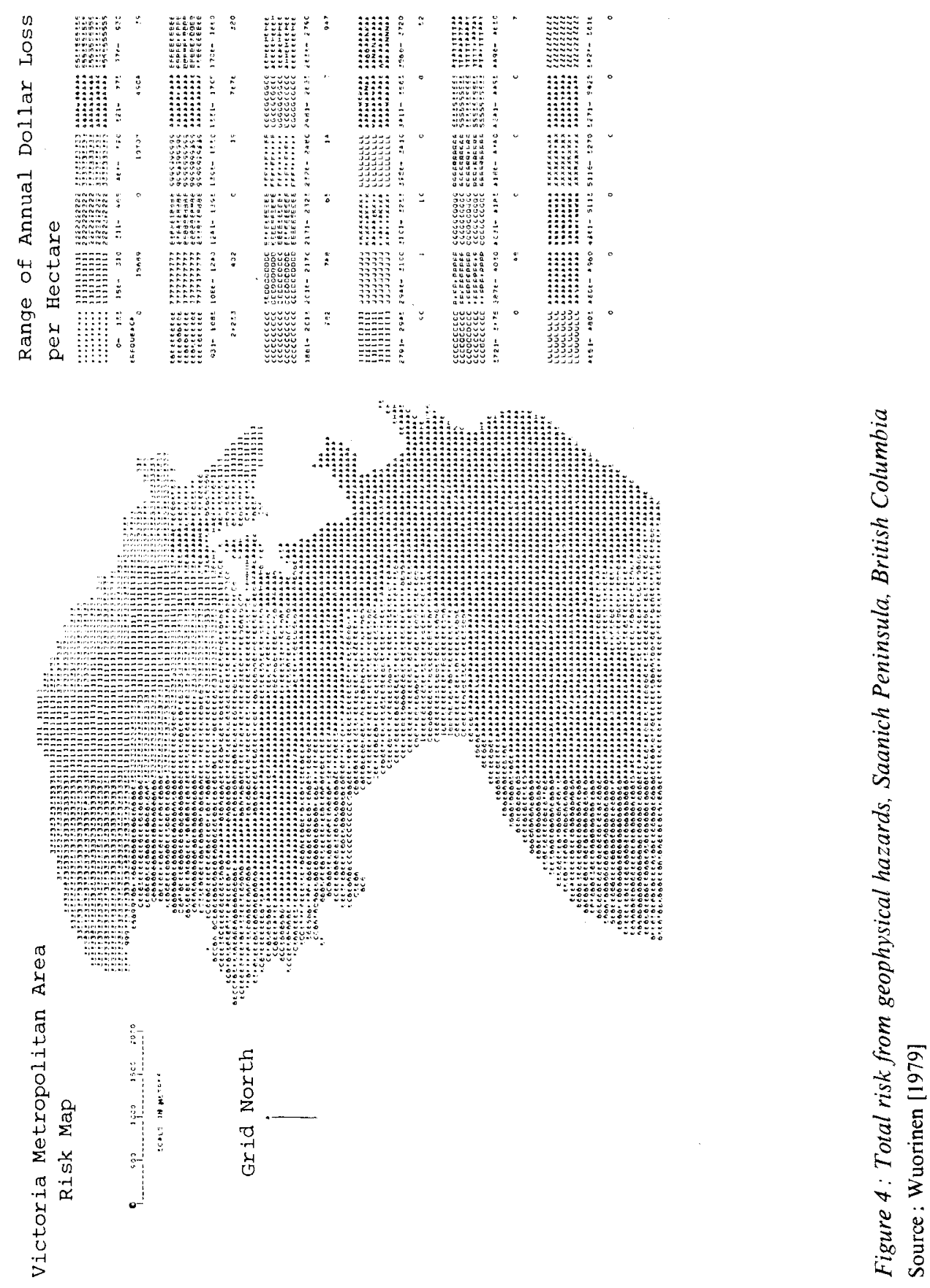
procedure has been established in the United Kingdom for summarizing the evidence in an anonymous way, while in the United States the Engineering Performance Information Center has been established to carry out this task (Rodin [1978]). As Knoll [1978] has pointed out, it is this second approach to guaranteeing structural integrity that is most commonly in use within the engineering and architectural professions. Indeed many alterations to building codes and standards have been the result of adverse experience with existing regulations elsewhere. This approach gains in validity with the size of the data bank on structural performance in disaster.

An alternative third approach to ensuring the stability of a structure is to design it so that it will not collapse even after certain critical components have lost their effectiveness. To this end, the design is manipulated to establish alternative load pathways so that there is a broad level of protection even against unanticipated hazards. A fourth method involves analyzing the social consequences of failure. Structures are ranked according to their significance and higher standards set for those that pose the greatest risk. In the United Kingdom, for example, this approach has been taken for bridge and dam design (Rodin [1978]).

Numerous accidents and even some disasters have occurred because of an incompatibility between machines and their operators. There are many reasons why this problem is increasing. Technology is becoming ever more complex and, as a result, relatively high levels of intelligence and rigorous training are often required to operate and maintain it. In some cases the effects of the operation of this equipment is such that its health and environmental ramifications are not fully understood by its operators. At the same time, sophisticated machinery is being used in societies where there is no reservoir of technological expertise. Illiteracy may be endemic or instructions may be given or parts identified in a language unfamiliar to its potential operators. In addition, the widespread use of drugs and alcohol and problems of mental illness may temporarily or permanently impair an individual's ability to handle dangerous materials or sophisticated systems.

Ideally, one of the best approaches to mitigating the consequences of deficiencies in buildings, machines or operators is the use of fail-safe principles. This basic concept involves the design of a system so that it functions with negative (self-correcting) rather than positive (accelerating) feedback. In this way systems can be built which, even if they fail to function as expected, will do so in a manner that is not dangerous. Large transport trucks illustrate this principle (Adcock [1978]). These are normally equipped with brakes that are held off by air pressure. If this pressure is lost because of some malfunction, the brakes automatically go on, stopping the vehicle and so reducing the possibility of disaster. Traffic lights are normally designed to turn to red should a failure occur. In this way all traffic is obliged to stop, preventing accidents.

The safety committee should actively attempt to make sure that, as far as possible, buildings and equipment used in their community operate on this principle. Although it is very difficult to apply at an urban infrastructural scale, it can often be used to prevent small threats from developing into larger ones. The equipping of buildings with sprinkler systems which are activated by heat is an example of its increasing application.

A forgiving environment for failures is created when planners, architects, and designers assume a relatively high incidence of destruction or misuse and try to minimize its consequences. It is possible to contemplate applying this principle at a variety of different levels. For example, when designing a land use policy, care must be taken to 
ensure that should the destruction of one component, such as a chemical factory or oil refinery, occur, this does not cause secondary disasters among adjacent land uses. To provide such a degree of safety, disaster simulations are essential. These should allow the definition of zones of risk around major noxious facilities in which other development is strictly controlled. This is rarely the case. In their survey of London, Ontario, Hewitt and Burton [1971] determined that at least $50 \%$ of all industrial premises were situated too near to their neighbours, perhaps making them susceptible to chain reactions in disaster situations. Forgiving environments must also be created within buildings. For example, highrise apartments should have helicopter pads on their roofs and be designed to minimize the spread of smoke during fires.

Buildings must seek to accomodate both the commonplace and the exceptional. On relatively rare occasions fires, explosions, bomb threats, inclement weather, or earthquakes may necessitate rapid evacuation. This need poses both design and management problems. Although the evacuation of structures has been a major concern of building codes for over 50 years, its scientific and technological base is insecure. Pauls [1977], for example, has pointed out that many building codes contain errors in their regulations governing the width of exit stairs and riser tread geometry. The latter is often based on a simple length, and even the units of measurement were different from those today. Pauls claims that, as a result, exit stair treads are normally about two inches too shallow, a deficiency with considerable time consequences in evacuation. It has also been determined that under normal circumstances about $3 \%$ of those usually present in highrise office buildings cannot or should not attempt to evacuate by means of crowded stairways. These include individuals with obvious physical disabilities, or who suffer from heart disorders, or are convalescents from recent illness, accidents, or surgery. This problem becomes even more acute in hospitals, homes for the elderly, and some other institutions. Every care must be taken in the design of such buildings that they can in fact be evacuated rapidly. Stairways, for example, must be capable of accommodating both wheelchairs and stretchers when elevators are out of service or too dangerous to use.

It is easier to destroy than to create. Yet, unfortunately, the act of destruction is often associated with substantial benefits for those responsible. Such advantages may include publicity, prestige, economic gain, and increased power. In consequence, deliberate damaging acts against people and property are occurring with increasing regularity. This spectrum of destruction stretches from vandalism, arson and sabotage to riot, civil war, and invasion. Security in design, aimed at preventing or at least reducing such damage, is becoming of ever-increasing significance.

This is not a new concept, having given rise to such diverse structures as the Great Wall of China and the Tower of London. The moat, the portcullis, and the turret are all historically significant building innovations designed to increase security. What is new is the scale and diversity of possible acts of aggression and therefore the variety of threats that society must seek to guard against. Many design and construction strategies can be used to reduce the risks of vandalism and other forms of deliberate destruction. It is possible, for example, to include the probable incidence of such damage in total risk microzonations and to locate vulnerable properties in areas where it is least likely to occur. In addition, if willful damage and its ramifications are to be minimized, then the architect and engineer must take its possibility into account during design, in the same way that they seek to minimize weathering, wear, decay, or corrosion. Miller [1973] termed this 
concept " building self-defence". In his study of damage caused by vandalism he was able to establish obvious links between design and types of materials used in construction and subsequent losses. For example, the use of light coloured soft wall finishes, large glass panes, felt, asbestos cement roofs, or copper piping was felt to invite vandalism. Open spaces in design, such as those under stairs or between buildings and walls, were to be avoided.

Another alternative for buildings that are righ security risks or of special significance for critical operations is to construct them underground. Alternatively, a wide variety of security devices are becoming available, telephone-computer networks, seismic, electromagnetic, infrared and ultrasonic sensors and two-way television monitoring. Such devices are designed to minimize the delay between a problem developing and an adequate response occurring.

\section{Disaster Simulations and Predictions}

All societies undergo change as the result of their experiences. It is, however, too costly to rely on such a learning process in the case of disasters. Every community should seek, therefore, to improve its performance during disaster by simulating damaging events and gaining experience from such surrogates (Figure 2).

There are a variety of techniques available to assist in this process. Disaster simulation methods include scale models, such as the large accelerator used at the Tsukuba Research Center in Education City, Japan, to reproduce seismic waves and study their impact on buildings. Analogue models and computer simulations can also be used to permit relatively accurate predictions of potential disaster losses. Figure 5, for example, is a computer simulation of damage that would be caused in the city of Victoria from an earthquake reaching a modified Mercalli intensity VIII on normal ground (Foster and Carey [1976]). The design of all such models involves three basic steps : the production of risk maps, the determination of the geographical location and characteristics of the population and infrastructure at risk, and the development of a matrix representing the loss relationship between property type and the intensity of disaster agent impact. They can be prepared for any hazard. In addition to such modelling, scenarios (Ericksen [1975]) and the Delphi technique (Smil [1974]) can be used to predict the nature of potential losses over the longer term.

It is inadequate to merely simulate disasters. Planners must seek to influence the selection of a less hazardous futurity by the community and to encourage optimum responses to disaster threats. Various techniques are available to assist in this process. They include gaming which is used to model real world decision making and field exercises. Both can be of great value in preparing to reduce disaster impact.

For example, the Canadian federal government has been conducting gaming to test contingency plans for an oil spill in the Beaufort Sea, in the southeastern corner of the Arctic Ocean. There has already been exploratory offshore drilling in this harsh and delicate environment (Mansfield and Hoffman [1979]). Exercise BREX III was carried out in 1978 to test Canadian ability to deal with a serious oil spill in this area. It involved a combination of scenario development, resource and exercise control staffs, and simulations of development and radio/landline communications through eight operating centres 


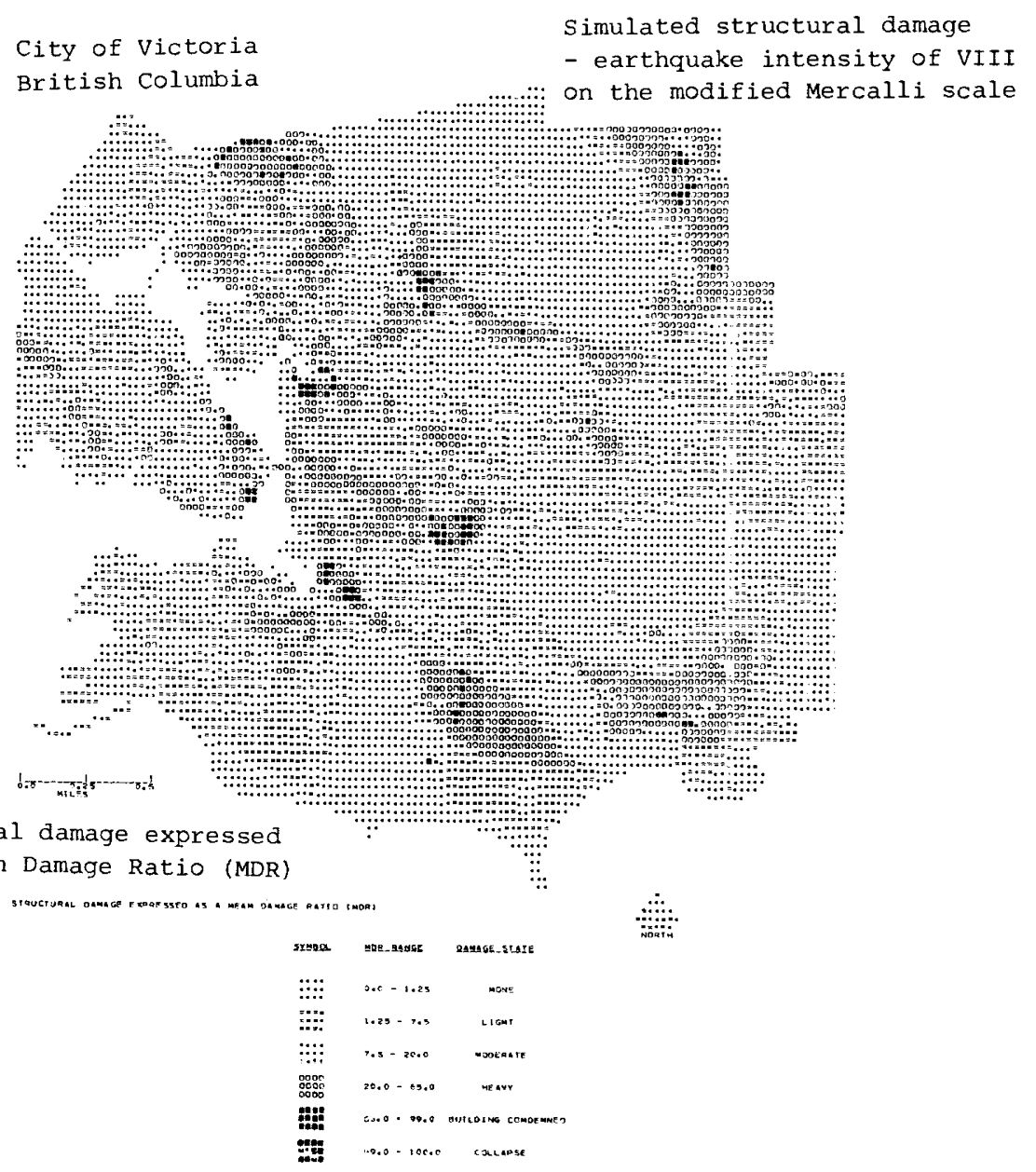

Simulated earthquake damage in intensity VIII.

Figure 5: Simulated damage in Victoria from an earthquake reaching a modified Mercalli intensity VIII on normal ground. Source : Foster and Carey [1976]. 
connected by special telephones. Approximately 80 participants from government and industry took part in the game ; it lasted $2-1 / 2$ days in the Territorial Government offices, Whitehorse, Yukon.

Probably one of the most comprehensive of all disaster games is ATLANTIS, the Simulation Exercise in Disaster Relief Management developed by Ritchie and the International Systems Corporation of Lancaster (G. N. Ritchie [1978], personal communication). This game is designed to provide a realistic simulation in which the techniques of resouce management in disaster can be practiced. It lasts for between 2 to 4 days and requires up to 15 players acting singly or in pairs to represent national ministries on a National Disaster Emergency Committee. The exercise follows a pattern of free play with participants being responsible for policy decisions and plans for executive action.

When disaster actually strikes, weaknesses in planning become immediately apparent and crucial time and personnel must be used to compensate for such inadequate arrangements. This lack of rehearsal also leads to unfamiliarity with existing procedures and facilities by both the officials responsible for their ultimate implementation and by the public in general. To avoid this error the safety program coordinator and his committee can organize field exercises to simulate disaster. These should be based upon the more likely emergencies that the community might actually have to respond to. To ensure that they are as realistic as possible field exercises should be preceded by the application of some of the techniques previously described. The use of models and computer simulations, for example, might provide data on the scale of probable damage and the number and distribution of potential casualties. Scenarios and gaming can help predict social response. This information is invaluable in making certain that disaster field exercises realistically portray the impact of particular hazards.

The value of such field exercises was demonstrated in Topeka, Kansas, where yearly simulations are held to coincide with the start of the tornado season. When the community was actually damaged in 1966 its disaster plans and the personnel responsible for their implementation proved to be very effective, due in no small part to their constant rehearsal (Parr [1969]). Even when the field exercises have not dealt with the type of disaster that actually later befalls a community, they can still be of great value in improving response. In October 1974 a research team from Ottawa's Carleton University visited Sydney, Nova Scotia, following a destructive wind storm. Its purpose was to evaluate the community's response to this disaster. The evaluation proved very positive and included the assertion that reaction had probably been so effective because of a field exercise held in the community some 16 months before (Scanlon and Jefferson [1975]). This was the case despite the fact that the actual disaster experienced was a wind storm while the simulated event was the collapse of a wing of the Sydney Academy, a local high school. Numerous differences occurred between simulated and actual casualties, damage, and threats. Nevertheless, it was concluded that the field simulation had been of great value for two reasons. First, it gave some persons direct experience of the problem of handling a disaster, especially with decision making under stress and with emergency communications. Second, Scanlon and Jefferson saw such field exercises as being a major stimulus to community awareness of the need for a disaster response. Many of those who took part in the field simulation were very willing to play similar, or more responsible roles, in the actual disaster. Having seen the value of disaster exercises, the city appears ready to hoid them regularly. 


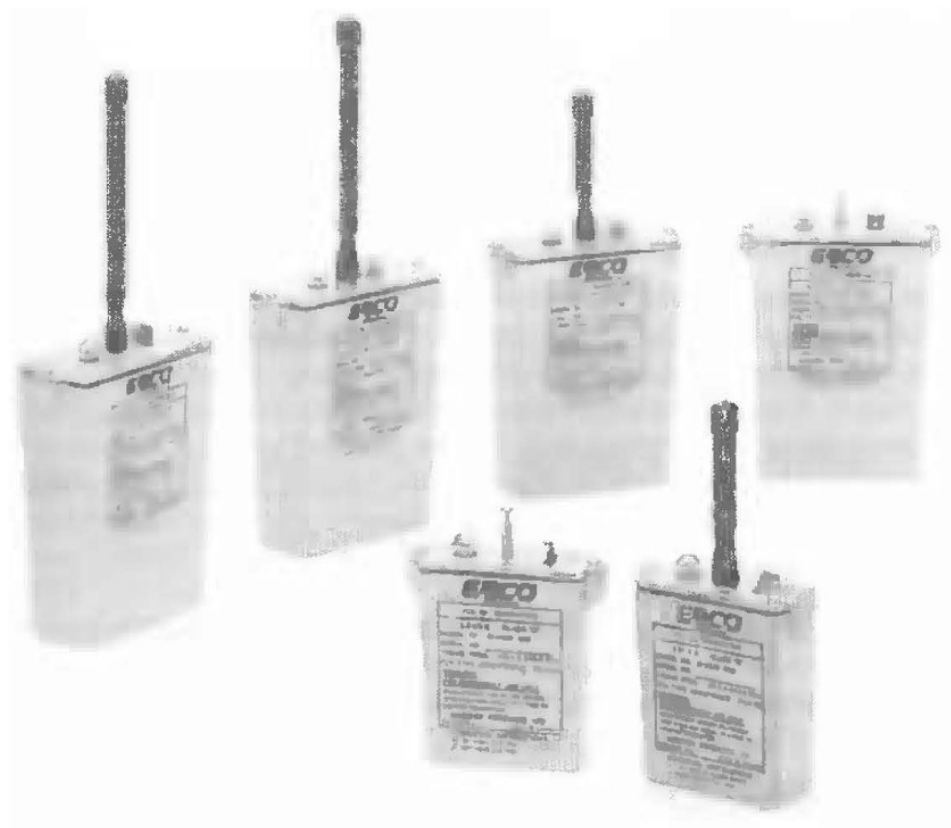

B-CON $200 B$ EPIRB CHARACTERISTICS

FCC Type Acceptance Par 83 Marine Class B

Operating Frequencies $\quad 121.5 \mathrm{MHz}$. and $243.0 \mathrm{MHz}$.

Power Output $\quad .75$ Watt

Emission Type A9

Modulation Swept Tone

Operating Life Up to 10 Days

Operating Temperatures $\quad-30^{\circ} \mathrm{C}$ to $60^{\circ} \mathrm{C}$

Battery Shelf Life 5 lears

Battery Replacement 2 Years

Battery Type D Cell Alkalitie

Activation Manual on/off/test Switch, Guarded

Operating Indicator LED

Full Function Test Circuit Yes

Range

Size

250 Miles

9 " High by $5^{\prime \prime}$ Diameter

Weight

Mounting

5 Pounds

Bracket

$\begin{array}{ll}\text { Immersion } & \text { Waterproof, Buoyant } \\ \text { Antenna } & \text { Rubber Duck }\end{array}$

Warranty

io Years Excluding Batteries

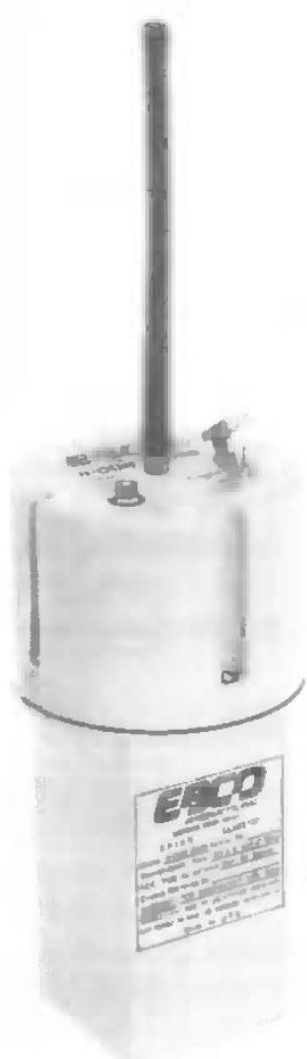

Figure 6: An emergency position indicating radio beacon

Source: Goldring [1982]. 


\section{Warning systems}

A viable local community safety plan usually includes provisions for the operation of efficient hazard warning systems. Although these networks vary in size, scope and effectiveness, reflecting their social setting and the characteristics of the hazard being monitored, they increasingly involve the use of sophisticated technology and the cooperation of a variety of organizations and individuals.

An interesting new technological development is the manufacture of small electronic equipment capable of linking the public directly to major warning networks. Examples include the various classes of Emergency Position Indicating Radio Beacons (EPIRB) which, with the flick of a switch, transmit on either aircraft emergency frequencies or VHF channels 15 and 16, the latter being the international distress channel which is monitored continuously in many countries (Goldring [1982]). Canada, the United States, France and the Soviet Union are combining through project SARSAT (Search and Rescue, Satellite Aided Tracking) to launch a series of satellites which will scan the earth's surface once every 24 hours for such emergency signals. The system is expected to become fully operational in 1983 with the launching of a new series of TIROS weather satellites which will carry locator equipment. New technology permits EPIRBS to be worn on the belt or carried in a pocket, allowing explorers, boaters, fishermen and others to be located anywhere on the earth's surface (Figure 6).

Figure 7 demonstrates the complexity of a typical warning network, and indicates that there are usually 16 basic steps involved in the operation of such systems. Information

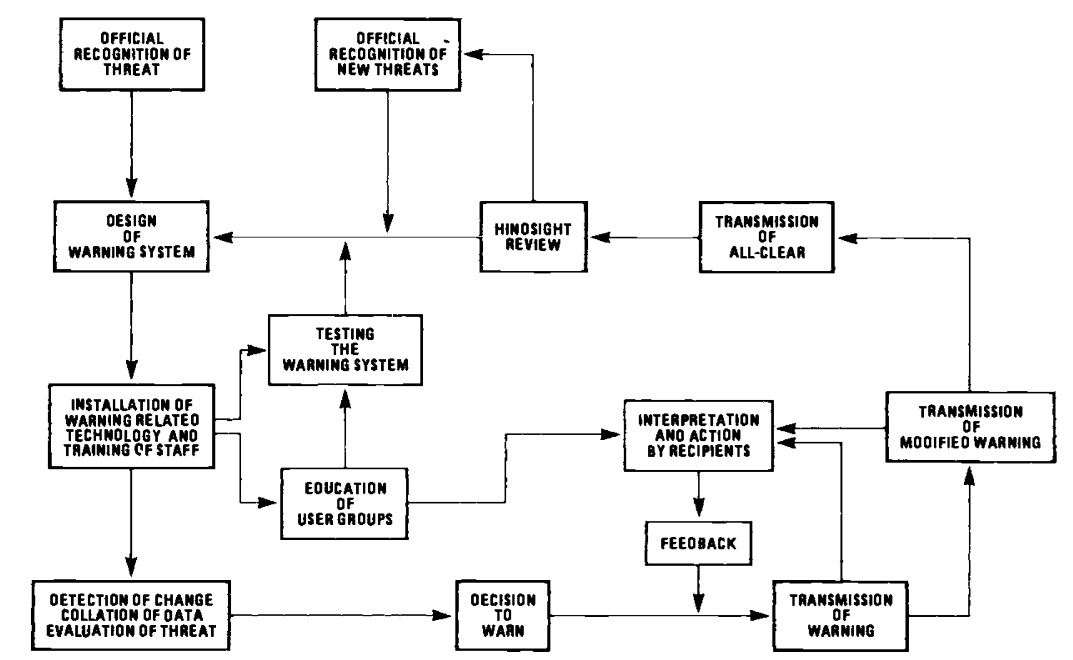

SOUACE: Storr (1009)

Figure 7 : Idealized warning system

Source : Foster [1980]. 
must flow both ways through warning networks, both to and from those at risk. The way in which individuals and families respond to disaster warnings has been studied by both sociologists and psychologists (Killian [1952]; Fritz [1957]; Drabek [1969]). Three important generalizations can be drawn from this research (Table 6).

\section{Table 6 : Factors influencing response to disaster warnings}

1. Any warning message broadcast, especially the early ones, will be accepted at face value only by a minority of the recipients. Most will engage in confirmation efforts for a time.

2. The more warning messages received by an individual, the fewer the attempts at warning confirmation.

3. The closer a person is to the target of a warning, the higher the incidence of face-to-face communication and the larger the number of sources used in confirmation attempts.

4. Warnings from official sources (police, state patrol, fire department) are more likely believed.

5. Message content per se influences belief. The more accurate and consistent the content across several messages, the greater the belief.

6. The more personal the manner in which a message is delivered, the more it will be believed.

7. Belief in eventual impact increases as the number of warnings received increases.

8. The recipient's sense of the sender's certainty about the message is important to belief.

9. Message believability is related to what happens in the confirmation process. The response of official sources to questions which call for validation, corroboration, or refutation helps determine believability.

10. A person is more likely to believe a warning of impending danger to the extent that perceived changes in his physical environment support the threat message.

11. Persons who see others behaving as if they believe a warning to be valid are themselves more likely to believe the warning.

12. Past experience may render current warnings less credible if disaster is not part of experience, or more credible if disaster is part of experience.

13. The closer a person is to the target area of warning, the more rumors he will hear and the less accurate will be his understanding of the character of the forecast events.

14. Persons do not readily evacuate on the basis of the first warning received, and the number of warnings received thereafter is directly related to evacuation.

15. As the warning message increases in its accuracy, and/or information about survival choices, and/or consistency with other warnings, and/or clarity about the nature of the threat, the probability of adaptive response increases.

16. Whether or not a person takes action depends on his belief in the warning message. But even if he believes, he may fail to take adaptive action due to his misinterpretation of the meaning of the message content.

(continues) 
17. Evacuation tends to be a family phenomenon. The best way to accomplish evacuation appears to be repeated authoritative messages over broadcast media which stimulate discussion within the family and lead to evacuation (if it is going to happen at all).

18. Persons receiving face-to-face warnings in a family setting from authorities are more likely to evacuate.

19. Persons with recent disaster experience are more likely to take protective actions.

20. Perceived amount of time to disaster impact is also important.

21. Belief that impact could occur at the location from which a person may be about to evacuate is critical.

22. Older persons are less likely than the young to receive warnings regardless of warning source, and less likely to take protective actions.

23. Regardless of the content of a warning message, people tend to define some potential impact in terms of prior experience with that specific disaster agent.

Source: Haas [1973] and Mileti [1975].

Firstly, even though a wide variety of individuals may receive the same warning message, each hears and believes different things. Secondly, people respond to such warnings on the basis of what they hear encourages them to behave. Thirdly, individuals are stimulated differently, depending on who they are, who they are with, and who and what they see (Mileti [1975]). In summary, warning systems must be designed to promote appropriate responses in those at risk. They must, therefore, aim not merely at the linear transmission of a message but to operate as a system with appropriate feedback loops to ensure the necessary response has occurred. If this does not take place, major life loss can occur, even when considerable time is available for evacuation or the occupation of shelters, as was the case during the May 23, 1960 Hawaiian tsunami (Lachman, Tatsuoka and Bank [1961]).

\section{Disaster plans}

Emergencies are characterized by four distinguishing features: an urgent need for rapid decisions accompanied by acute shortages of the necessary trained personnel, materials, and time to carry them out effectively. Even under normal conditions decision making is a complicated process which involves such steps as problem definition, the ranking of objectives, the establishing of criteria, and the recognition of constraints. Alternative strategies for achieving objectives must be evaluated, programs compared, and the consequences of particular actions estimated. Once these stages in the decision making process have been carried out, plans must be drawn up, implemented, and their related performances and impacts evaluated (Mitchell [1971]). The complexity of this process is increasing and under normal circumstances several years may elapse between problem identification and plan implementation. In emergency situations such a process is clearly impractical. Victims trapped beneath fallen buildings, on the roofs of burning highrises, 
or caught in rapidly submerging residences cannot afford the luxury of bureaucratic procrastination. Similarly, social services such as hospitals or welfare agencies may suddenly be called upon to provide aid on a scale far beyond normal. Without careful preplanning, breakdowns in emergency decision making inevitably leads to inferior performance, heightening disaster losses.

Since under normal circumstances municipal decision making is a complicated and protracted process, a well-designed disaster plan should seek to identify the types of decisions that are likely to arise during an emergency situation. Procedures for dealing with them must be established beforehand and the process of government streamlined to allow immediate yet optimum responses when disaster strikes. The safety plan coordinator and his committee should play a major role in making sure that such a document is prepared, circulated, and tested. While every community has special needs and capabilities which should be reflected in its planning, it is possible to provide a general disaster plan format. This is outlined in Table 7.

\section{Table 7: Typical contents of a disaster plan}

1. Policy statement on value of disaster planning by chief executive officer.

2. Legislative authority for the design of the disaster plan and for the steps it contains.

3. Aims of the plan and conditions under which it comes into force.

4. Assessment of community disaster probabilities.

5. Disaster scenarios.

6. Relationships with other levels of government, particularly emergency-related agencies.

7. Authority organization chart.

8. List of names, addresses, and telephone numbers of all relevant agencies, their heads and deputies.

9. Operation of warning systems :

(1) types of warnings ;

(2) distribution ;

(3) obligations on receiving warnings.

10. Preimpact preparations :

(1) relationships between type of disaster agent and necessary preparations;

(2) responsibilities of different agencies;

(3) location of greatest risk sites.

11. Emergency evacuation procedures :

(1) conditions under which evacuation is authorized;

(2) routes to be followed and destinations;

(3) accommodating the special needs of the elderly, ill, or institutionalized.

12. Shelters:

(1) locations ;

(2) facilities.

(continues) 
13. Disaster control centre and subcentres:

(1) location(s) ;

(2) equipment ;

(3) operation ;

(4) staffing.

14. Communications.

15. Public information.

16. Search and rescue :
(1) responsibilities;
(2) equipment ;
(3) areas most likely to require servicing.

17. Community order.

18. Medical facilities and morgues:
(1) location ;
(2) transportation;
(3) capacity ;
(4) facilities.

19. Restoration of community services:
(1) order of priorities ;
(2) responsibilities.

20. Protection against continuing threat :

(1) the search for secondary threats;

(2) actions to be taken if discovered.

21. Continuing assessment of total situation :
(1) responsibilities ;
(2) distribution.

22. Reciprocal agreements and links with other municipalities.

23. Testing the plan :

(1) disaster simulations ;

(2) simulation evaluations.

24. Revision and updating of the plan.

25. Plan distribution.

\section{Planning for reconstruction}

The phase during which a community is recovering from disaster can conveniently be subdivided into four overlapping periods (Haas, Kates and Bowden [1977]). Typically, each is approximately ten times the length of that preceding it. In the first of these, the emergency period, the disaster plan is normally in operation and attention is paid to pressing agent-generated and response-generated demands. The problems caused directly and indirectly by destruction and by the associated needs of the dead, injured, homeless, 
and missing provide the focus of attention. During this period normal social and economic activities are suspended or greatly modified. Depending on the nature of the disaster agent, scale of loss, and the preparedness and capacity of the society to respond to disaster, the emergency period may last for as little as a few days or as long as several weeks. It can be considered over when search and rescue operations have ceased, major transportation arteries have been cleared and are functioning once more, emergency mass feeding has been reduced, and immediate temporary housing needs have been met. The emergency period lasted for between three to four weeks in Managua, Nicaragua following the earthquake of 23 December 1972. In contrast, it occupied only approximately one week in Anchorage, Alaska, after the 27 March 1964 seismic event (Kates and Pijawka [1977]).

The emergency period gives way to one of restoration, characterized by repairs to utilities, commercial, industrial, and residential structures. Those buildings that cannot be salvaged will be demolished and efforts will be made to return to relatively normal economic and social activities. By the end of this restoration period, major urban services, transportation, and utilities are functioning effectively once more, debris has been removed, and those refugees who intend to return to their former community will have done so. In societies with a large resource base, these activities are usually completed within a few months, elsewhere restoration may take more than a year. This period lasted for only eight weeks in Anchorage following the 1964 earthquake and for some nine months after the Managua seismic shock (Kates and Pijawka [1977]).

During the replacement reconstruction period that follows, capital stocks are rebuilt and the economy recovers to predisaster levels or higher. This phase ends when population has returned to its predisaster level and losses in jobs, residences, and urban activities have been compensated for. Certain types of reconstruction will be undertaken long after this phase is over but will be concerned with major projects. Typically, replacement reconstruction takes several years to complete, lasting, for example, for some three years in Rapid City, South Dakota after the 9 June 1972 flood.

During the replacement reconstruction period, the city generally is in a phase of flux. Dislocation inevitably follows any major disaster. Once the altruistic response to the initial impact has subsided a chain reaction of relocation, displacement, and further relocation is begun by industry and commerce and by residents capable of paying the highest rents or prices for land and property. Evolutionary patterns produced by the operation of market forces are accelerated because of the urgent need of these individuals and organizations to return to normal (Bowden, Pijawka, Roboff, Gelman, and Amaral [1977]). These forces are not restricted to damaged locations but affect a far larger part of the region. As a rule, in excess of two or three times the area is required to relocate activities from a devasted city core.

Those businesses such as banks and other financial institutions that are part of a large chain or have easy access to local capital characteristically relocate in prime locations. Similarly, long-established businesses and those with comprehensive predisaster insurance are able to meet higher land and property prices. This process was demonstrated in the rebuilding of San Francisco, where the financial institutions were among the first to relocate. In contrast, the less financially secure, smaller scale businesses are typically forced to relocate on the periphery of the commercial area. It was here in the reconstruction of San Francisco that wholesaling and industrial firms, transient residential operations, and 
tenements for unskilled workers and low-ranked ethnic minorities were relocated (Haas, Trainer, Bowden, and Bolin [1977]). In summary, during the replacement reconstruction period, those sectors of the economy that have traditionally dominated quickly tend to re-establish their positions of control. At the opposite end of the scale, small, undercapitalized, commercial and industrial activities may go bankrupt or leave the city completely. This process occurred in both San Francisco and Managua, leading to a decline in diversity.

The lower on the pecking order, the greater the stress, appears to be true also of socioeconomic status. In the residential sector, upper and upper-middle class individuals capable of refinancing home reconstruction or paying high rents relocate first. The lower the socioeconomic class of the individual, the more frequently market forces will create the need to make post-disaster moves and the longer the period of deferral of eventual residential stability is likely to be. In addition, such individuals will be faced with the fewest housing alternatives and be most likely to be obliged to permanently leave the city. The problem is compounded since such residents are also probably employed in low-ranking economic activities, those that are the least able to recover quickly. For this reason, those low on the socioeconomic scale may also be faced with longer periods of job dislocation and unemployment.

In the case of post-1900 disasters, a $10 \%$ of population has normally been replaced in three years and a $50 \%$ loss in seven years. Other factors such as financial aid and the availability of human resources and materials appear to have a less obvious impact on the speed of recovery. Indeed, Harbridge House [1972] could find no relationship between government assistance and the speed of economic recovery in major United States disasters occurring between 1960 and 1970. Despite the regularity of the relationship between disaster magnitude and rate of recovery, some eities apparently do take abnormally long or short time periods to regain their former status. A significant factor that influences their speed of recovery appears to be uncertainty, the removal of which as rapidly as possible must be a major aim of local government. It is in the provision of direction that the safety committee can play its major post-disaster role.

The simplest and most desirable way of achieving this end is through the preplanning of reconstruction. Ideally, every city should be prepared for recovery from the impact of a disaster agent. Long before devastation occurs, its planners should have produced blueprints for restoration and reconstruction. Unfortunately, this task is very rarely, if ever, accomplished, since recognition of the value of such preparation is extremely unusual. This widespread unwillingness to face up to the possibility of a major disaster increases the human suffering associated with adverse events when they do occur. It also reduces the chances of society benefiting from the opportunities for creative reconstruction that they present.

There appear to be many reasons why restoration and reconstruction plans do not sit alongside those for emergency response on the bookshelves of local government officials. Although widespread destruction occurs frequently on a global basis, individual communities almost always live with the comforting belief that they will never have to face the harsh reality of post-disaster recovery. Federal and regional governments are often confused over which of their departments, if any, should have the mandate to assist financially and technically with such disaster planning. As a result, monetary and technical aid for it is unlikely to be available. 
Ideally, such post-disaster planning should be the final step in the disaster mitigation process (Figure 2). Plan contents should be based on estimates of death and destruction arrived at by the application of scale and mathematical models, the Delphi technique, scenario building, gaming, and field exercises. This process of compiling restoration and reconstruction plans in response to a variety of different disaster scenarios can have numerous beneficial spinoffs, even if the damage actually suffered is not that predicted. Such planning can lead to a greater awareness of deficiencies in existing policies and legislation. It will almost certainly highlight the need for new legal instruments that allow governments the rapid compulsory purchase of land in high risk areas after devastation. It will also demonstrate that mechanisms must be developed to permit expeditious changes in land use and building codes and to encourage the design of an emergency activated streamlining of the established decision making process so that it is capable of coordinating dramatic post-disaster change in the city's infrastructure. Planning for reconstruction also pinpoints deficiencies in the existing data base, yet allows the luxury of time in which to correct those weaknesses.

Kates and Pijawka [1977] recognized a fourth phase in the recovery of a city from disaster which they termed the commemorative, betterment, and developmental reconstruction period. During this final recovery stage, building serves three differing but often interrelated functions : commemoration of the disaster, formation of future growth and development, or marking the city's post-disaster betterment or improvement. Characteristically, such projects are very large in scale and are financed by public funds. Usually their implementation occupies a time period double the length of the replacement reconstruction phase. Examples include the buildings of the monumental civic centre complex between 1915 and 1929 in San Francisco, following the earthquake of 1906. Similarly, the development and betterment of specific locations such as the Fourth Avenue landslide area took some ten years to complete in Anchorage, Alaska, after the 1964 destruction.

\section{Conclusions}

Much of society's risk taking is by junior governments, yet many of the resulting losses must be carried by national and international governments and insurance companies. If disasters are to be reduced, these bodies must encourage local authorities to plan comprehensively to reduce risk. This paper has briefly discussed an interrelated series of steps that can be taken to achieve this worthwhile objective. It is no longer adequate to refer to disasters as Acts of God, in the final analysis our society will suffer the catastrophes it deserves.

\section{REFERENCES}

ADCOCK, H.W. [1978]: “The engineer's obligations as related to man-made hazards", ASCE-ICE-CSCE 1978 Joint Conference on Predicting and Designing for Natural and Man-Made Hazards, American Society of Civil Engineers, New York, 39-48. 
BOWDEN, M. J., PIJAWKA, D., ROBOFF, G. S., GELMAN, K. J., and AMARAL, D. [1977] : "Re-establishing homes and jobs: Cities", in Reconstruction Following Disaster, J. E. Haas, R. W. Kates, and M. J. Bowden (Eds.), MIT Press, Cambridge, Massachusetts, 69-145.

CRANDELL, D. R., and WALDRON, H. H. [1969] : "Volcanic hazards in the Cascade range ", in Geologic Hazards and Public Problems, R. A, Olson and M. M. Wallace (Eds.), Region Seven, Office of Emergency Preparedness, Santa Rosa, California, 5-18.

DRABECK, T. E. [1969]: "Social process in disaster: Family evacuation", Social Problems, 16, 336-349.

ERICKSEN, N. H. [1975]: Scenario Methodology in Natural Hazards Research, Institute of Behavioral Science, The University of Colorado, program on Technology, Environment and Man, Monograph NSF-RA-E-75-010.

FOSTER, H. D. [1975]: "Disaster mitigation: A geomorphological contribution", Emergency Planning Digest, 2(5), 2-9.

FOSTER, H. D., and CAREY, R. F. [1976]: "The simulation of earthquake damage", in Victoria Physical Environment and Development, Harold D. Foster (Ed.), Vol, 12, Western Geographical Series, University of Victoria, B.C., 221-239.

FOSTER, H. D. [1980] : Disaster Planning: The Presentation of Life and Property, Springer-Verlag, New York.

FOSTER, H. D. [1981] : "Reducing disaster losses: The management of environmental hazards", in Canadian Resource Policies: Problems and Prospects, B. Mitchell and W.R.D. Sewell (Eds.), Methuen, Toronto, 209-232.

FRITZ, C. E. [1957]: " Disasters compared in six American communities", Human Organization, 16 (Summer), 6-9.

GOLDRING, J. [1982] : Modern Products Ltd., P.O. Box 683, Victoria, B.C., personal communication.

GRAY, C. [1982] : "This atlas displavs our most morbid details", Canadian geographic, 102(4), $72-76$.

HAAS, J. E. [1973] : "What every good news director ought to know about disaster warnings ”, paper presented at the Radio and Television News Directors' Association Session on Natural Disasters, Seattle, Washington, October 10-11, Institute of Behavioral Science, University of Colorado, Boulder, Colorado.

HAAS, J. E., KATES, R.W., and BOWDEN, M. J. [1977] : Preface to Reconstruction Following Disaster, J.E. Haas, R.W. Kates, and M. H. Bowden (Eds.), MIT Press, Cambridge, Massachusetts, xv-xxiv.

HAAS, J. E., TRAINER, P. B., BOWDEN, M. H., and BOLIN, R. [1977] : “Reconstruction issues in perspective", in Reconstruction Following Disaster, J. E. Haas, R. W. Kates, and M. H. Bowden (Eds.), MIT Press, Cambridge, Massachusetts, 25-68.

HARBRIDGE HOUSE [1972]: An Inquiry into the Long Term Economic Impact of Natural Disasters in the United States, prepared for the Office of Technical Assistance, Economic Development Administration, U.S. Department of Commerce, Harbridge House, Boston.

HEWITT, K., and BURTON, I. [1971]: The Hazardousness of a Place: A Regional Ecology of Damaging Events, University of Toronto Press, University of Toronto Department of Geography Research Series Publication, Toronto, Ontario.

HOWE, G. M. [1979] : “ Death in London”, The Geographical Magazine, 51(4), 284-289.

KARNIK, V. [1972]: "Microzoning program within the UNDP-UNESCO survey of the seismicity of the Balkan region ", Proceedings of the International Conference on Microzonation for Safe 
Construction Research and Application, NSF, UNESCO, University of Washington, ASE and Academy of Mechanics, Seattle, Washington, 213-216.

KATES, R. W. [1970] : Natural Hazards in Human Ecological Perspective : Hypotheses and Models, Natural Hazards Research Working Paper No. 14, University of Toronto Press, Toronto, Ontario.

KATES, R.W., and PIJAWKA, D. [1977]: "From rubble to monument: The pace of reconstruction", in Reconstruction Following Disaster, J. E. Haas, R. W. Kates, and M. H. Bowden (Eds.), MIT Press, Cambridge, Massachusetts, 1-23.

KILLIAN, L. M. [1952]: "The significance of multi-group membership in disaster", American Journal of Sociology, 57, 309-314.

KNOLL, F. [1978]: "Discussion of Jack Rodin's predicting man-made hazards - State of the art", ASCE-ICE-CSCE 1878 Joint Conference on Predicting and Designing for Natural and Man-Maáe Hazards, American Society of Civil Engineers, New York, 33-38.

LACHMAN, R., TATSUOKY, M., and BANK, J. W. [1961] : " Human behavior during the tsunami of May 1960 ", Science, 133, 1405-1409.

MANSFIELD, B., and HOFFMAN, J. [1979] : "Government contigency plans for the Beaufort Sea ", Emergency Planning Digest, 6(1), 15-19.

MILETI, D. S. [1975] : Natural Hazard Warning Systems in the United States: A Research Assessment, program on Technology, Environment and Man, Institute of Behavioral Science, University of Colorado, Boulder, Colorado.

MILLER, A. [1973] : "Vandalism and the architect", in Vandalism, C. Ward (Ed.), Architectural Press, London, 96-111.

MITCHELL, B. [1971] : A Framework for Decision Making in Water Management: A Review and Commentary, Department of Geography, University of Waterloo, Waterloo, Ontario.

MURRAY, M. A. [1967]: "Geography of death in the United States and the United Kingdom ", Annals, Association of American Geographers, 57(2), 301-314.

NOVA [1980]: The Cancer Detectives of Lin Xian, British Broadcasting Corporation and WGBH Educational Foundation, Boston, Massachusetts.

PAULS, J. L. [1977] : Management and Movement of Building Occupants in Emergencies, National Research Council of Canada, Division of Building Research, Paper No. 788, 104-130.

PUGET SOUND COUNCIL OF GOVERNMENTS [1975a] : Regional Disaster Mitigation Plan for the Central Puget Sound Region, Puget Sound Council of Governments.

PUGET SOUND COUNCIL OF GOVERNMENTS [1975b]: Regional Disaster Mitigation Technical Study for the Central Puget Sound Region, Puget Sound Council of Governments.

RODIN, J. [1978] : " Predicting man-made hazards - State of the art", ASCE-ICE-CSCE 1978 Joint Conference on Predicting and Designing for Natural and Man-Made Hazards, American Society of Civil Engineers, New York.

SCANLON, J., and JEFFERSON, J. [1975] : “ The Sydney simulation ”, Emergency Planning Digest, 2(6), 2-7.

SMIL, V. [1974]: Energy and the Environment: Long Range Forecasting Study, Manitoba Geographical Studies 3, Department of Geography, The University of Manitoby, Winnipeg, Manitoba.

SMITHSONIAN INSTITUTION [1971] : Natural Disaster Research Centers and Warning Systems : A Preliminary Survey, Smithsonian Institution, Cambridge, Massachusetts. 
STEINBRUGGE, K. V. [1970]: "Earthquake damage and structural performance in the United States", in Earthquake Engineering, R. L. Wiegel (Ed.), Prentice-Hall, Englewood Cliffs, New Jersey.

SULLIVAN, W [1979]: “Tangshan, 1976: Worst destruction since Hiroshima ", report from New York Times, Victoria Times, June 27, 5.

VITALIANO, D. B. [1973] : Legends of the Earth: Their Geologic Origin, Indiana University Press, Bloomington, Indiana.

WUORINEN, V. [1979]: "A methodology for mapping total risk in urban areas", unpublished $\mathrm{Ph}, \mathrm{D}$. dissertation, Department of Geography, University of Victoria, Victoria, British Columbia. 